\title{
Dehydroepiandrosterone in systemic lupus erythematosus
}

\author{
Amr H Sawalha ${ }^{1,2,3}$ and Susan Kovats ${ }^{3}$ \\ 1 US Department of Veterans Affairs Medical Center, Oklahoma City, OK \\ 2Department of Medicine, University of Oklahoma Health Sciences Center, Oklahoma City, OK \\ 3Arthritis and Immunology Program, Oklahoma Medical Research Foundation, Oklahoma City, OK.
}

\begin{abstract}
Dehydroepiandrosterone (DHEA) is a weak androgen that exerts pleomorphic effects on the immune system. The hormone has no known receptor, and consequently, the mechanism of action of DHEA on immunocompetent cells remains poorly understood. Interestingly, serum levels of DHEA are decreased in patients with inflammatory disease including lupus, and these levels seem to inversely correlate with disease activity. Following encouraging studies demonstrating beneficial effects of DHEA supplementation in murine lupus models, a number of clinical studies have tested the effect of DHEA administration in lupus patients. DHEA treatment could improve patient's overall quality of life assessment measures and glucocorticoid requirements in some lupus patients with mild to moderate disease, however, the effect of DHEA on disease activity in lupus patients remains controversial. Long term safety assessment studies are required in light of the reported effect of DHEA supplementation in lowering HDL cholesterol in lupus patients.
\end{abstract}

\section{Introduction}

Dehydroepiandrosterone (DHEA), and its metabolite dehydroepiandrosterone sulfate (DHEAS) are the most abundant circulating human adrenal steroids. DHEA is a weak androgenic steroid, synthesized from $17 \alpha$-hydroxypregnenolone, and primarily secreted by the adrenal cortex in response to stress [reviewed in (1)]. DHEA is also produced by the gonads, GI tract and the brain. DHEA is metabolized primarily to androstenedione (ASD), as well as multiple additional bioactive androgens and estrogens (Fig. 1). DHEA becomes sulfated to form DHEA-Sulfate (DHEAS), a metabolic end-product, which may be converted back to DHEA in peripheral tissues.

Normal serum levels of DHEA range from 1-50 nM, with higher levels in males. Serum levels of DHEAS are $\sim 20 \varepsilon \mathrm{M}$. Serum concentrations of androgens, including DHEA, DHEAS and ASD peak in young adulthood and decrease with age, declining to levels 10-20\% of their peak values by age 80 (2). Serum levels of adrenal androgens also are decreased during chronic inflammatory disease, including rheumatoid arthritis and lupus (3-5). When reviewing the results of published studies of the effects of DHEA on immune cells in culture or in vivo, it is important to note whether cells were exposed to physiological (nanomolar) or supraphysiological (micromolar) amounts of DHEA, since high levels of DHEA may elicit effects that do not reflect normal physiology. In addition, the study of DHEA in murine models may not accurately represent humans since comparatively little DHEA is produced by non-primate

Please address correspondence to Amr H. Sawalha MD; 825 N.E. $13^{\text {th }}$ Street, MS\#24, Oklahoma City, Oklahoma 73104. Phone: (405) 271-7977. Fax: (405) 271-4110. Email: E-mail: amr-sawalha@omrf.ouhsc.edu. Or to Susan Kovats PhD; 825 N.E. 13 ${ }^{\text {th }}$ Street, MS\#24, Oklahoma City, Oklahoma 73104. Phone: (405) 271-8583. Fax: (405) 271-4110. Email: E-mail: susan-kovats@ omrf.ouhsc.edu. 
adrenal glands and steroid metabolism via $17 \alpha$-hydroxylase occurs differently between primates and rodents (1).

\section{Biological effects of DHEA}

Since DHEA is a precursor of both androgens and estrogens, its biological effects could be due to direct effects of DHEA on a specific receptor or indirect via its bioactive steroid metabolites. A specific receptor for DHEA has not been cloned. However, high affinity $\left(K_{d} 1.4-14 \mathrm{nM}\right)$ binding sites specific for DHEA, and not downstream metabolites, have been identified in the plasma membrane, cytoplasm or whole cell extracts of some cell types, including human and murine lymphocytes, monocytes and vascular endothelial cells [reviewed in (6)]. The existence of a specific receptor for DHEA is also suggested by data showing that physiological levels of DHEA elicit rapid cellular signaling, including $G$ protein activation $(7,8)$ and regulation of the mitogen-activated protein kinase (MAPK) pathway (9). In aortic endothelial cells, a plasma membrane binding activity of $\mathrm{K}_{\mathrm{d}} 49 \mathrm{pM}$ was linked to immediate $\mathrm{G}$ protein and endothelial nitric oxide synthase (eNOS) activation $(7,8)$. This binding activity was not inhibited by DHEAS, estradiol, testosterone, pregnenolone, or ASD. Murine T lymphocytes exposed to 0.1-100 nM DHEA increased their secretion of IL-2, and a specific DHEA binding activity in the cytoplasm with a $\mathrm{K}_{\mathrm{d}}$ of 1.4-2.7 $\mathrm{nM}$ was identified (10). Exposure of human monocytes to $10 \mathrm{pM}-100 \mathrm{nM}$ DHEA increased lipopolysaccharide (LPS)-stimulated IL-1 production, which was associated with a specific cellular binding activity of $\mathrm{K}_{\mathrm{d}} 5-10 \mathrm{nM}$ (11). Identification of a specific DHEA receptor would greatly facilitate studies of the mechanism by which DHEA exerts its physiological effects.

\section{DHEA and the immune system}

\section{Effects of DHEA on immune cell function}

DHEA has apparently paradoxical effects on immunity, which are summarized in recent comprehensive articles $(1,2)$. Numerous reports indicate that DHEA may improve immune cell function by regulating the production of pro-inflammatory cytokines such as IL-2, IL-1, IL-6 and TNF $\alpha$. DHEA was reported to increase immune function after trauma hemorrhage or thermal damage, decrease mortality after sepsis, and increase resistance to viral and bacterial infections $(12,13)$. Of note, metabolites of DHEA such as androstenediol and androstenetriol were significantly more potent than DHEA in protection of mice from lethal bacterial and viral infections, and in vitro, they promoted superior lymphocyte activation, suggesting that DHEA modulates immunity via its downstream metabolites rather than via a specific receptor (12).

In contrast, low levels of serum DHEA are associated with inflammatory disease including lupus, rheumatoid arthritis, and inflammatory bowel disease. While it remains unclear whether DHEA levels are reduced before or after autoimmune disease onset, these observations suggest that DHEA promotes pathways that dampen chronic pro-inflammatory immune responses and foster maintenance of self-tolerance.

One hypothesis to explain these two apparently opposing roles of DHEA (e.g. increasing resistance to infection and decreasing autoimmunity) is that DHEA regulates immune system homeostasis by promoting the appropriate magnitude and resolution of an inflammatory immune response, such that the host does not suffer extensive immune-mediated pathology or lymphocyte reactivity to self tissues. For example, DHEA may help modulate immunity after stress-induced immune suppression. In a murine model, hemorrhage and trauma was associated with increased TNF $\alpha$, IL-1 and IL-6 production and decreased splenocyte IL-2 or IFN $\gamma$ production; levels of these cytokines were restored to normal levels by DHEA administration during resuscitation (14). 
DHEA is metabolized to estrogens and other androgens including testosterone, which themselves act via estrogen or androgen receptors to regulate immune cell development and function (15-18). Immune cells, including macrophages metabolize DHEA (19), and there is some evidence that sex steroid metabolism by peripheral blood mononuclear cells (PBMC) changes with aging (20). As mentioned above, it remains unclear whether the beneficial effects of DHEA on the outcome of trauma or infection are due to action of DHEA on a specific cellular receptor or to its metabolites. Indeed, estradiol administration during trauma hemorrhage also decreased immune suppression and detrimental TNF $\alpha$ production, and promoted host recovery (21).

\section{Effects of DHEA on cytokine production by immune cells}

The majority of studies investigating the effects of DHEA on immune cells have focused on alterations in pro-inflammatory cytokine production. Since these studies recently have been reviewed comprehensively (1), here we provide a few examples of studies that used physiological levels of DHEA.

Myeloid cells_DHEA was found to regulate production of IL-6 and TNF $\alpha$ by several cell types. The age related decline in serum androgen levels (DHEA, DHEAS and ASD in females and DHEAS in males) was correlated with elevated IL-6 levels in both mice and humans (22). There was no correlation with TNFa or IL-2 levels, suggesting specific effects on IL-6. In vitro, DHEA at the physiological concentration of $1-5 \times 10^{-8} \mathrm{M}$ inhibited PBMC production of IL-6 induced by LPS (22). In aging mice, the altered regulation of IL-6 levels was restored by administration of exogenous DHEA (23). These data suggest that one mechanism by which DHEA regulates immunity is by decreasing production of IL-6, a pleiotropic cytokine involved in many pro-inflammatory pathways. However, other studies showed that $10^{-12}-10^{-9} \mathrm{M}$ DHEA synergized with LPS to increase secretion of IL- 6 and TNF $\alpha$ by human monocytes (24).

Lymphocytes-Although several studies have reached the conclusion that DHEA promotes $\mathrm{T}_{\mathrm{H}} 1$ mediated cellular immunity, other reports suggest that DHEA enhances $\mathrm{T}_{\mathrm{H}} 2$ immunity [reviewed in (1)]. The conflicting conclusions regarding the role of DHEA in regulating the balance of type 1 and type 2 cytokine responses may be due to differences in the infectious or autoimmune disease models themselves, or to technical variables such as the amount and time of DHEA exposure or the mouse genetic background.

DHEA $(<1 \mathrm{nM})$ was shown to enhance mitogen stimulated IL-2 production by human and murine T cells $(10,25,26)$. DHEA, at normal physiologic concentrations, has been shown to increase IL-2 production from stimulated normal CD4+ human T cells in vitro (25). A low level of IL-2 production in lupus T cells, independent of disease activity, has been well described (27). This defect in IL-2 production is due to transcriptional repression $(28,29)$ and has been suggested to result in defective autoreactive $\mathrm{T}$ cell clearance by activation-induced cell death (30). Interestingly, DHEA treatment of lupus CD4+ T cells in vitro restores IL-2 secreting capacity to normal levels, suggesting that impaired IL-2 production by lupus T cells might be a result of low serum DHEA levels $(5,31)$.

\section{Potential molecular mechanisms of DHEA action in immune cells}

The ability of DHEA or its downstream metabolites to protect mice from lethal bacterial infection and LPS challenges was associated with decreased TNF $\alpha$ and IL-1 production. Several reports have shown that DHEA decreases production of TNF $\alpha$, IL-1, and IL-6 via its ability to inhibit the activation of the transcription factor NF- $\kappa \mathrm{B}(32,33)$. Diet exposure to DHEAS decreased constitutive NF- $\kappa \mathrm{B}$ activity and pro-inflammatory cytokine production in spleens of aging mice via activation of PPAR $\alpha$ activation (32). Activated PPAR $\alpha$ inhibits 
binding of NF- $\kappa$ B to DNA and prevents dissociation of the inhibitor I $\kappa \mathrm{B}$. DHEA also was reported to inhibit DNA binding of the AP-1 transcription factor (34).

In a human T cell line associated with high affinity DHEA binding sites (26), DHEA was found to negatively regulate the mitogen-activated protein kinase (MAPK) pathway via a novel mitogen-activated protein phosphatase that negatively regulates p38 MAPK (9). These data suggest that DHEA mediates its anti-inflammatory effects by suppressing the MAPK pathway in activated lymphocytes. Interestingly, B lymphocytes in SLE patients showed increased amounts of activated p38 MAPK directly ex vivo, in comparison to normal controls, which correlates with reduced DHEA levels in these patients (35).

\section{Use of DHEA to modulate disease in murine lupus models}

Preclinical studies in murine models of SLE indicated that oral administration of DHEA impregnated in food beginning at 2 months of age led to decreased severity of lupus-like disease in $(\mathrm{NZB} \times \mathrm{NZW})_{\mathrm{F} 1}$ mice. Initial studies showed that DHEA prolonged survival and decreased production of anti-dsDNA antibodies (36). Subsequent studies showed that DHEA also prevented splenomegaly and decreased the expression of IL-6 and IL-10, both of which are normally associated with disease progression $(37,38)$. Oral administration of DHEAS at 2 months of age also prolonged survival, decreased serum anti-dsDNA antibodies and IL-10, but this benefit was not found if DHEAS was first administered at 6 months of age (39). These data suggest that the beneficial effect of DHEA occurs before disease onset, and that DHEA does not significantly ameliorate ongoing disease. Again it is unclear whether the diseaseprotecting effects of DHEA during murine lupus are due to DHEA itself or androgen metabolites. Dihydrotestosterone or testosterone treatment of female lupus-prone mice improved survival and decreased glomerulonephritis; correspondingly, castration of male lupus-prone mice increased incidence of lupus (40).

\section{Use of DHEA in lupus patients}

Studies in murine models and humans suggest that alterations in neuroendocrine regulatory mechanisms involving the hypothalamic-pituitary-adrenal (HPA) axis may promote chronic inflammation [reviewed in $(1,2)$ ]. In chronic inflammatory diseases such as lupus and rheumatoid arthritis, andrenal androgens are low relative to the cortisol concentration, suggesting that steroid synthesis shifts toward production of glucocorticoids $(3,4)$. Proinflammatory cytokines such as IL- $1 \beta, \mathrm{TGF} \beta$ and TNF $\alpha$ were shown to reduce expression of enzymes required for synthesis of adrenal androgens [reviewed in (2)].

Levels of both DHEA and DHEAS are low in female lupus patients compared to healthy controls $(5,31)$. Indeed, the level of both metabolites is more reduced in lupus patients with active disease compared to patients with inactive disease, suggesting a potential role for low DHEA levels in the pathogenesis of lupus (5). Several studies have examined the role for DHEA supplementation in lupus patients, often with conflicting results (41). The rationale behind these studies was the known effects of DHEA on the immune system, the low serum levels of DHEA in lupus patients, and the favorable outcome in lupus animal models after DHEA supplementation (discussed in detail above).

Van Vollenhoven and colleagues studied the effect of DHEA at an oral dose of $200 \mathrm{mg} / \mathrm{day}$ in ten female lupus patients with mild to moderate disease (42). After 6 months of therapy, there was a significant reduction in Systemic Lupus Erythematosus Disease Activity Index (SLEDAI) scores (from 10.0 \pm 2.9 to $4.9 \pm 1.7, \mathrm{p}=0.04$ ) and a significant improvement in patient's overall assessment scores. Further, in patients who were on corticosteroid therapy at baseline, there was a significant reduction in the average daily corticosteroid dose requirement both at 3 months and at 6 months following DHEA therapy (42). Subsequently, this open label 
study was extended to include 50 female lupus patients (40 additional lupus patients) who received DHEA at doses ranging from 50-200 mg/day (43). 21 patients (42\%) continued DHEA for the entire 12 months period of the study and showed significant improvement in SLEDAI scores, and patient's and physician's overall assessment, and a reduction in concurrent prednisone dose usage after 12 months of DHEA therapy as compared to baseline (43). The high rate of drop out from the study was attributed to lack of efficacy in $30 \%$ of patients, side effects in $16 \%$, and other reasons in $12 \%$ of patients. The most common side effects were acne occurring in $62 \%$ of premenopausal patients and $31 \%$ of postmenopausal patients, and hirsutism occurring in $22 \%$ of premenopausal and $8 \%$ of postmenopausal lupus patients (43).

Following the initial studies reporting beneficial effects of DHEA supplementation in lupus patients, a double-blind randomized and placebo controlled trial in 28 female lupus patients with mild to moderate disease was performed (44). Lupus patients either received DHEA 200 $\mathrm{mg} /$ day or placebo for a duration of 3 months. Although the study reports an improvement in SLEDAI scores and physician's overall assessment of disease activity, and a reduction of concurrent prednisone doses and in the occurrence of lupus flares in patients receiving DHEA, none of these differences was statistically significant (44). The study also reports an improvement in patient's overall assessment (adjusted $p$ value $=0.022$ ), however, this difference does not pass the threshold for significance after correcting for multiple testing in this study. The same group studied the effect of DHEA at a dose of $200 \mathrm{mg}$ /day in lupus patients with a more severe disease characterized by the presence of lupus nephritis, hemolytic anemia, thrombocytopenia, or serositis (45). Nineteen patients were enrolled and analyzed in this randomized double-blind, placebo-controlled trial; 9 patients received DHEA and 10 received placebo for 6 months. No significant difference was observed in the mean improvement of SLEDAI scores between the groups, the Systemic Lupus Activity Measure (SLAM) scores, physician's and patient's global assessment scores, prednisone dosage requirement, or erythrocyte sedimentation rate (45). Interestingly, however, patients on placebo had a significant reduction in bone mineral density at the lumbar spine at 6 months compared to baseline, while no significant reduction was seen in the patients who received DHEA (45). All patients in this study were receiving calcium and vitamin D supplementation. In another study measuring endogenous DHEAS in the serum of 37 premenopausal female lupus patients, a positive correlation was observed between DHEAS levels and bone mineral density in both the lumbar spine and femoral neck (46). Further, there was a negative correlation between serum DHEAS levels and serum intact parathyroid hormone levels, suggesting a possible mechanism by which reduced DHEAS levels can result in loss of bone density (46). However, administration of DHEA $200 \mathrm{mg} /$ day for 1 year did not affect bone mineral density in the lumbar spine in a double-blind placebo-controlled study of premenopausal female patients with quiescent lupus (47).

In a multicenter randomized, double-blind placebo controlled trial, Chang et al studied the effect of DHEA in 120 female patients with mild to moderate lupus (48). DHEA $200 \mathrm{mg} / \mathrm{day}$ was given to 61 patients, while 59 patients received placebo for 6 months. While the mean reduction in SLAM and SLEDAI scores were similar in the two groups, there was a significant improvement in the patient's assessment score in the DHEA treatment group ( $\mathrm{p}=0.005)$ (48). Moreover, there was a reduction in the number of patients with a disease flare in the treatment group versus placebo over the 6-months duration on the study (18.3\% versus 33.9\%) (48).

Petri et al addressed the effect of DHEA treatment on corticosteroid requirement in a doubleblind, randomized placebo controlled trial in 191 female lupus patients (49). Patients were randomized to receive DHEA at $100 \mathrm{mg} / \mathrm{day}$, or $200 \mathrm{mg} /$ day, or placebo for 7-9 months. In patients with active SLE at baseline (defined by a SLEDAI score of >2), a significant sustained reduction of corticosteroid requirement was noted between lupus patients who received DHEA $200 \mathrm{mg} /$ day and placebo. Sustained reduction in prednisone dosage $(\leq 7.5 \mathrm{mg} /$ day for at least 
the last 2 months of the follow up period) was achieved in $51 \%$ of lupus patients treated with DHEA $200 \mathrm{mg} / \mathrm{day}$ compared to only $29 \%$ in the placebo group ( $\mathrm{p}=0.031)$ (49). These findings suggest that DHEA at a dose of $200 \mathrm{mg} /$ day might reduce prednisone requirement in lupus patients with active disease (SLEDAI>2), while maintaining stabilization or reducing disease activity. The most common side effect in the DHEA treatment group was acne, which was generally mild but occurred twice as frequently in the treatment group compared to placebo (41\% in the DHEA groups compared to $19 \%$ in the placebo group) (49).

The effect of DHEA on disease activity was subsequently studied in another randomized, double-blind, placebo-controlled trial that was performed in 27 centers in the US (50). A total of 381 female lupus patients were randomized to receive DHEA $200 \mathrm{mg} / \mathrm{day}$ or placebo for up to 12 months. Patients in both groups continued taking their baseline lupus medications that included oral corticosteroids (prednisone $\leq 10 \mathrm{mg} /$ day or equivalent), hydroxychloroquine, and immunosuppressive agents. There was no difference at baseline between the treatment and the placebo groups with regards to age, race, menopause status, disease activity scores, and therapeutic experience. Response was defined in this study as no evidence for deterioration, and stabilization or improvement of two disease activity scores (SLEDAI and SLAM) and two quality of life measures (patient's global assessment and Krupp Fatigue Severity Scale).

Response rate differences were not statistically significant between the two groups $(51.3 \%$ in the DHEA treatment group versus $42.2 \%$ in the placebo group, $\mathrm{p}=0.074)(50)$. However, in patients with active disease at baseline (SLEDAI $>2$ ) response rate was $58.5 \%$ in the treatment group as compared to $44.5 \%$ in the placebo group ( $\mathrm{p}=0.017$ ). While DHEA treatment was generally well tolerated, $14.3 \%$ of patients in the treatment group did not complete the study due to adverse events, primarily androgenic in nature (50). Of concern, there was a significant reduction in HDL levels in lupus patients treated with DHEA compared to placebo, which was evident by 3 months of DHEA administration (50). This significant reduction in HDL cholesterol was also reported in a 6-month study using small doses of DHEA (20-30 mg/day) in female lupus patients (51). The latter study showed a beneficial effect of low dose DHEA in health-related quality of life, particularly mental well-being and sexuality, in steroid-treated female lupus patients (51).

In conclusion, DHEA might have some effect in improving quality of life measures in lupus patients with mild to moderate disease, however, data regarding its effect on disease activity remain controversial. Side effects of DHEA treatment were reportedly mild. Nonetheless, in light of the reported reduction of HDL cholesterol levels in lupus patients receiving DHEA, long term safety needs to be further studied, particularly since lupus patients have an increased risk of atherosclerotic heart disease (52).

\section{Acknowledgments}

This publication was made possible by funding to A.S. from NIH Grant Number P20-RR015577 from the National Center for Research Resources, the Arthritis National Research Foundation and the University of Oklahoma College of Medicine, and to S.K. from the Alliance for Lupus Research and the Oklahoma Center for the Advancement of Science and Technology.

\section{References}

* of importance

** of major importance

**1. Dillon JS. Dehydroepiandrosterone, dehydroepiandrosterone sulfate and related steroids: their role in inflammatory, allergic and immunological disorders. Curr Drug Targets Inflamm Allergy 2005;4 (3):377-385.385 [PubMed: 16101547] This comprehensive review article summarizes studies in which DHEA and related steroids were used to modulate the immune system during health or 
disease. This review also outlines potential confounding variables in studies of DHEA in vitro or in vivo.

2. Chen CC, Parker CR Jr. Adrenal androgens and the immune system. Semin Reprod Med 2004;22(4): 369-377. [PubMed: 15635504]

3. Masi AT, Da Silva JA, Cutolo M. Perturbations of hypothalamic-pituitary-gonadal (HPG) axis and adrenal androgen (AA) functions in rheumatoid arthritis. Baillieres Clin Rheumatol 1996;10(2):295332. [PubMed: 8911651]

4. Hedman M, Nilsson E, de la Torre B. Low sulpho-conjugated steroid hormone levels in systemic lupus erythematosus (SLE). Clin Exp Rheumatol 1989;7(6):583-588. [PubMed: 2533000]

**5. Lahita RG, Bradlow HL, Ginzler E, Pang S, New M. Low plasma androgens in women with systemic lupus erythematosus. Arthritis Rheum 1987;30(3):241-248.248 [PubMed: 3032210] This review summarizes evidence for a specific high affinity DHEA receptor in the plasma membrane, and for rapid signaling events mediated by this putative receptor.

6. Widstrom RL, Dillon JS. Is there a receptor for dehydroepiandrosterone or dehydroepiandrosterone sulfate? Semin Reprod Med 2004;22(4):289-298. [PubMed: 15635497]

7. Liu D, Dillon JS. Dehydroepiandrosterone activates endothelial cell nitric-oxide synthase by a specific plasma membrane receptor coupled to Galpha(i2,3). J Biol Chem 2002;277(24):21379-21388. [PubMed: 11934890]

8. Liu D, Dillon JS. Dehydroepiandrosterone stimulates nitric oxide release in vascular endothelial cells: evidence for a cell surface receptor. Steroids 2004;69(4):279-289. [PubMed: 15183694]

9. Ashida K, Goto K, Zhao Y, Okabe T, Yanase T, Takayanagi R, et al. Dehydroepiandrosterone negatively regulates the $\mathrm{p} 38$ mitogen-activated protein kinase pathway by a novel mitogen-activated protein kinase phosphatase. Biochim Biophys Acta 2005;1728(1-2):84-94. [PubMed: 15777705]

10. Meikle AW, Dorchuck RW, Araneo BA, Stringham JD, Evans TG, Spruance SL, et al. The presence of a dehydroepiandrosterone-specific receptor binding complex in murine T cells. J Steroid Biochem Mol Biol 1992;42(3-4):293-304. [PubMed: 1351401]

11. McLachlan JA, Serkin CD, Bakouche O. Dehydroepiandrosterone modulation of lipopolysaccharidestimulated monocyte cytotoxicity. J Immunol 1996;156(1):328-335. [PubMed: 8598481]

*12. Loria RM. Immune up-regulation and tumor apoptosis by androstene steroids. Steroids 2002;67(12): 953-966.966 [PubMed: 12398992] This review summarizes studies showing that adrenal androgens increase host resistance to viral and bacterial infections.

13. Loria RM, Padgett DA. Androstenediol regulates systemic resistance against lethal infections in mice. Arch Virol 1992;127(1-4):103-115. [PubMed: 1456887]

14. Jarrar D, Kuebler JF, Wang P, Bland KI, Chaudry IH. DHEA: a novel adjunct for the treatment of male trauma patients. Trends Mol Med 2001;7(2):81-85. [PubMed: 11286760]

15. Nalbandian G, Kovats S. Understanding sex biases in immunity: effects of estrogen on the differentiation and function of antigen-presenting cells. Immunol Res 2005;31(2):91-106. [PubMed: 15778508]

16. Kovats S, Carreras E. Regulation of dendritic cell differentiation and function by estrogen receptor ligands. Cell Immunol. 2008

17. Straub RH. The complex role of estrogens in inflammation. Endocr Rev 2007;28(5):521-574. [PubMed: 17640948]

18. Olsen NJ, Kovacs WJ. Effects of androgens on T and B lymphocyte development. Immunol Res 2001;23(2-3):281-288. [PubMed: 11444393]

19. Schmidt M, Kreutz M, Loffler G, Scholmerich J, Straub RH. Conversion of dehydroepiandrosterone to downstream steroid hormones in macrophages. J Endocrinol 2000;164(2):161-169. [PubMed: 10657851]

20. Hammer F, Drescher DG, Schneider SB, Quinkler M, Stewart PM, Allolio B, et al. Sex steroid metabolism in human peripheral blood mononuclear cells changes with aging. J Clin Endocrinol Metab 2005;90(11):6283-6289. [PubMed: 16091484]

21. Raju R, Bland KI, Chaudry IH. Estrogen: a novel therapeutic adjunct for the treatment of traumahemorrhage-induced immunological alterations. Mol Med 2008;14(3-4):213-221. [PubMed: 18235843] 
22. Straub RH, Konecna L, Hrach S, Rothe G, Kreutz M, Scholmerich J, et al. Serum dehydroepiandrosterone (DHEA) and DHEA sulfate are negatively correlated with serum interleukin-6 (IL-6), and DHEA inhibits IL-6 secretion from mononuclear cells in man in vitro: possible link between endocrinosenescence and immunosenescence. J Clin Endocrinol Metab 1998;83(6):2012-2017. [PubMed: 9626133]

23. Daynes RA, Araneo BA, Ershler WB, Maloney C, Li GZ, Ryu SY. Altered regulation of IL-6 production with normal aging. Possible linkage to the age-associated decline in dehydroepiandrosterone and its sulfated derivative. J Immunol 1993;150(12):5219-5230. [PubMed: 8515056]

24. Delpedro AD, Barjavel MJ, Mamdouh Z, Bakouche O. Activation of human monocytes by LPS and DHEA. J Interferon Cytokine Res 1998;18(2):125-135. [PubMed: 9506463]

25. Suzuki T, Suzuki N, Daynes RA, Engleman EG. Dehydroepiandrosterone enhances IL2 production and cytotoxic effector function of human T cells. Clin Immunol Immunopathol 1991;61(2 Pt 1):202211. [PubMed: 1833106]

26. Okabe T, Haji M, Takayanagi R, Adachi M, Imasaki K, Kurimoto F, et al. Up-regulation of highaffinity dehydroepiandrosterone binding activity by dehydroepiandrosterone in activated human $\mathrm{T}$ lymphocytes. J Clin Endocrinol Metab 1995;80(10):2993-2996. [PubMed: 7559886]

27. Murakawa Y, Takada S, Ueda Y, Suzuki N, Hoshino T, Sakane T. Characterization of T lymphocyte subpopulations responsible for deficient interleukin 2 activity in patients with systemic lupus erythematosus. J Immunol 1985;134(1):187-195. [PubMed: 3917275]

28. Solomou EE, Juang YT, Gourley MF, Kammer GM, Tsokos GC. Molecular basis of deficient IL-2 production in T cells from patients with systemic lupus erythematosus. J Immunol 2001;166(6):42164222. [PubMed: 11238674]

29. Tenbrock K, Tsokos GC. Transcriptional regulation of interleukin 2 in SLE T cells. Int Rev Immunol 2004;23(3-4):333-345. [PubMed: 15204092]

30. Tenbrock K, Juang YT, Kyttaris VC, Tsokos GC. Altered signal transduction in SLE T cells. Rheumatology (Oxford) 2007;46(10):1525-1530. [PubMed: 17586862]

31. Suzuki T, Suzuki N, Engleman EG, Mizushima Y, Sakane T. Low serum levels of dehydroepiandrosterone may cause deficient IL-2 production by lymphocytes in patients with systemic lupus erythematosus (SLE). Clin Exp Immunol 1995;99(2):251-255. [PubMed: 7851019]

32. Poynter ME, Daynes RA. Peroxisome proliferator-activated receptor alpha activation modulates cellular redox status, represses nuclear factor-kappaB signaling, and reduces inflammatory cytokine production in aging. J Biol Chem 1998;273(49):32833-32841. [PubMed: 9830030]

33. Du C, Khalil MW, Sriram S. Administration of dehydroepiandrosterone suppresses experimental allergic encephalomyelitis in SJL/J mice. J Immunol 2001;167(12):7094-7101. [PubMed: 11739531]

34. Dashtaki R, Whorton AR, Murphy TM, Chitano P, Reed W, Kennedy TP. Dehydroepiandrosterone and analogs inhibit DNA binding of AP-1 and airway smooth muscle proliferation. J Pharmacol Exp Ther 1998;285(2):876-883. [PubMed: 9580639]

*35. Grammer AC, Fischer R, Lee O, Zhang X, Lipsky PE. Flow cytometric assessment of the signaling status of human B lymphocytes from normal and autoimmune individuals. Arthritis Res Ther 2004;6 (1):28-38.38 [PubMed: 14979930] This early study showed that oral DHEA administration prolonged survival and prevented autoantibody generation in lupus prone mice, which provided a rationale for use of DHEA in human lupus patients.

36. Lucas JA, Ahmed SA, Casey ML, MacDonald PC. Prevention of autoantibody formation and prolonged survival in New Zealand black/New Zealand white F1 mice fed dehydroisoandrosterone. J Clin Invest 1985;75(6):2091-2093. [PubMed: 3159756]

37. Matsunaga A, Miller BC, Cottam GL. Dehydroisoandrosterone prevention of autoimmune disease in NZB/W F1 mice: lack of an effect on associated immunological abnormalities. Biochim Biophys Acta 1989;992(3):265-271. [PubMed: 2528378]

38. Yang BC, Liu CW, Chen YC, Yu CK. Exogenous dehydroepiandrosterone modified the expression of T helper-related cytokines in NZB/NZW F1 mice. Immunol Invest 1998;27(4-5):291-302. [PubMed: 9730089] 
39. Norton SD, Harrison LL, Yowell R, Araneo BA. Administration of dehydroepiandrosterone sulfate retards onset but not progression of autoimmune disease in NZB/W mice. Autoimmunity 1997;26 (3):161-171. [PubMed: 9550284]

40. Roubinian JR, Talal N, Greenspan JS, Goodman JR, Siiteri PK. Delayed androgen treatment prolongs survival in murine lupus. J Clin Invest 1979;63(5):902-911. [PubMed: 447833]

41. Olech E, Merrill JT. DHEA supplementation: the claims in perspective. Cleve Clin J Med 2005;72 (11):965-966. [PubMed: 16315437]968, 970-1 passim.

42. van Vollenhoven RF, Engleman EG, McGuire JL. An open study of dehydroepiandrosterone in systemic lupus erythematosus. Arthritis Rheum 1994;37(9):1305-1310. [PubMed: 7945493]

43. van Vollenhoven RF, Morabito LM, Engleman EG, McGuire JL. Treatment of systemic lupus erythematosus with dehydroepiandrosterone: 50 patients treated up to 12 months. J Rheumatol 1998;25(2):285-289. [PubMed: 9489820]

44. van Vollenhoven RF, Engleman EG, McGuire JL. Dehydroepiandrosterone in systemic lupus erythematosus. Results of a double-blind, placebo-controlled, randomized clinical trial. Arthritis Rheum 1995;38(12):1826-1831. [PubMed: 8849355]

45. van Vollenhoven RF, Park JL, Genovese MC, West JP, McGuire JL. A double-blind, placebocontrolled, clinical trial of dehydroepiandrosterone in severe systemic lupus erythematosus. Lupus 1999;8(3):181-187. [PubMed: 10342710]

46. Formiga F, Moga I, Nolla JM, Navarro MA, Bonnin R, Roig-Escofet D. The association of dehydroepiandrosterone sulphate levels with bone mineral density in systemic lupus erythematosus. Clin Exp Rheumatol 1997;15(4):387-392. [PubMed: 9272299]

47. Hartkamp A, Geenen R, Godaert GL, Bijl M, Bijlsma JW, Derksen RH. The effect of dehydroepiandrosterone on lumbar spine bone mineral density in patients with quiescent systemic lupus erythematosus. Arthritis Rheum 2004;50(11):3591-3595. [PubMed: 15529389]

**48. Chang DM, Lan JL, Lin HY, Luo SF. Dehydroepiandrosterone treatment of women with mild-tomoderate systemic lupus erythematosus: a multicenter randomized, double-blind, placebocontrolled trial. Arthritis Rheum 2002;46(11):2924-2927.2927 [PubMed: 12428233] These are two large multi-center randomized, double-blind, placebo-controlled trials that studied the effect of DHEA oral supplementation in lupus patients.

49. Petri MA, Lahita RG, van Vollenhoven RF, Merrill JT, Schiff M, Ginzler EM, et al. Effects of prasterone on corticosteroid requirements of women with systemic lupus erythematosus: a doubleblind, randomized, placebo-controlled trial. Arthritis Rheum 2002;46(7):1820-1829. [PubMed: 12124866]

**50. Petri MA, Mease PJ, Merrill JT, Lahita RG, Iannini MJ, Yocum DE, et al. Effects of prasterone on disease activity and symptoms in women with active systemic lupus erythematosus. Arthritis Rheum 2004;50(9):2858-2868.2868 [PubMed: 15452837] These are two large multi-center randomized, double-blind, placebo-controlled trials that studied the effect of DHEA oral supplementation in lupus patients.

51. Nordmark G, Bengtsson C, Larsson A, Karlsson FA, Sturfelt G, Ronnblom L. Effects of dehydroepiandrosterone supplement on health-related quality of life in glucocorticoid treated female patients with systemic lupus erythematosus. Autoimmunity 2005;38(7):531-540. [PubMed: 16373258]

52. van Leuven SI, Kastelein JJ, D'Cruz DP, Hughes GR, Stroes ES. Atherogenesis in rheumatology. Lupus 2006;15(3):117-121. [PubMed: 16634362] 


\section{Cholesterol}
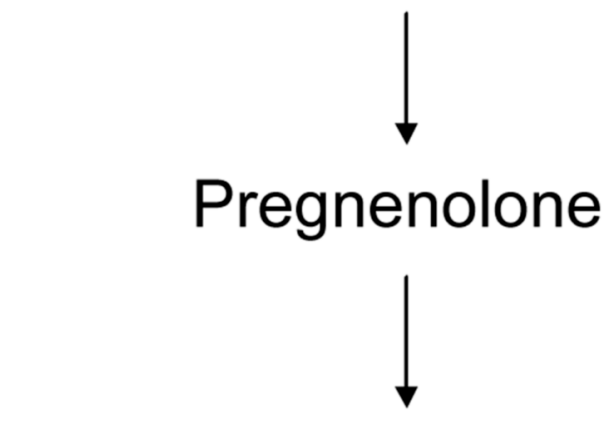

\section{7a-Hydroxypregnenolone}

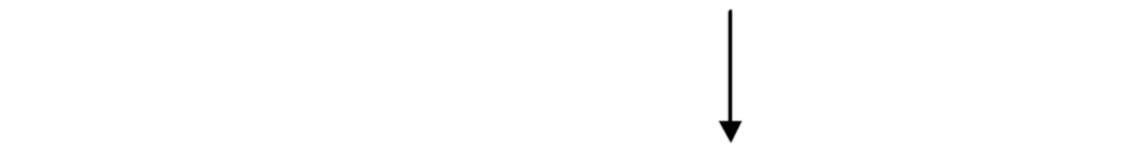

\section{DHEA sulfate $\Longleftrightarrow$ DHEA}

\section{Androstenedione}

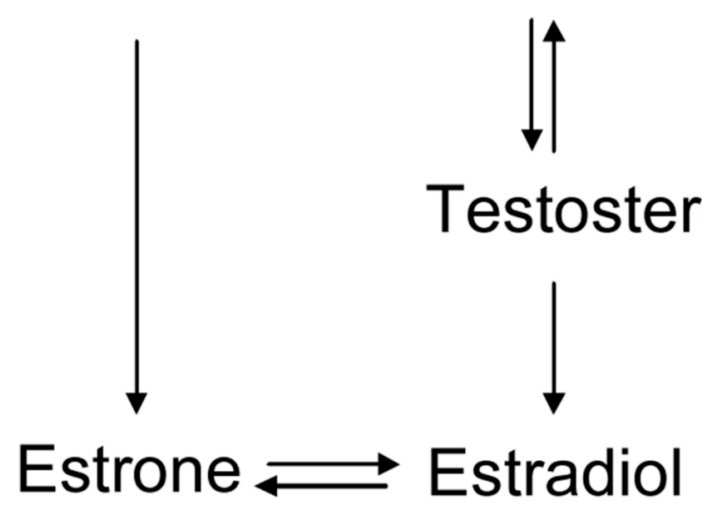

Fig. 1.

A schematic representation of dehydroepiandrosterone (DHEA) synthesis and metabolism. 